\title{
Current perspectives in herbal and conventional drug interactions based on clinical manifestations
}

\author{
Ajaykumar Rikhabchand Surana* ${ }^{*}$, Shivam Puranmal Agrawal, Manoj Ramesh Kumbhare and Snehal Balu Gaikwad
}

\begin{abstract}
Background: Herbs are an important source of pharmaceuticals. Herbs are traditionally used by millions of peoples for medicine, food and drink in developed and developing nations considering that they are safe. But, interaction of herbs with other medicines may cause serious adverse effects or reduces their efficacy. The demand for "alternative" medicines has been increased significantly, which include medicine derived from plant or herbal origin. The objective of this review article mainly focuses on drug interactions of commonly used herbs along with possible mechanisms. The method adopted for this review is searching of herb-drug interactions in online database.

Main text: Herb-drug interaction leads to pharmacological modification. The drug use along with herbs may show pharmacodynamic and pharmacokinetic interactions. Pharmacokinetic interaction causes alteration in absorption, distribution, metabolism and elimination. Similarly, pharmacodynamic interaction causes additive or synergistic or antagonist effect on the drugs or vice versa. Researchers had demonstrated that herbs show the toxicities and drug interactions like other pharmacologically active compounds. There is lack of knowledge amongst physician, pharmacist and consumers related to pharmacological action and mechanism of herb-drug interaction. This review article focuses on the herb-drug interaction of danshen (Salvia miltiorrhiza), Echinacea (Echinacea purpurea), garlic (Allium sativum), ginkgo (Ginkgo biloba), goldenseal (Hydrastis canadensis), green tea (Camellia sinensis), kava (Piper methysticum), liquorice (Glycyrrhiza glabra), milk thistle (Silybum marianum) and St. John's wort (Hypericum perforatum) along with probable mechanisms and clinical manifestation based on case studies reported in literature.
\end{abstract}

Conclusion: Herb-drug interactions may lead to serious side effects. Physician, pharmacist and patients must be more cautious while prescribing and or consuming these herbs.

Keywords: Herb-drug interactions, Danshen, Echinacea, Garlic, Gingko, Green tea

\section{Background}

Interaction is referred to as when the effect of one drug is changed due to the presence of another compound (food, herbal or drug) [1]. The demand for "alternative" medicines has been raised significantly, which include medicine derived from plant, animal and mineral source, i.e. herbal origin [2]. Herbal medications comprise of many phytochemicals, thus, may increase the chances of herb-drug interactions (HDIs) [3]. The global dietary

\footnotetext{
* Correspondence: ajaysurana01@rediffmail.com

S.M.B.T. College of Pharmacy, Dhamngaon Tal Igatpuri, Dist Nashik, M.S. 422403, India
}

\section{Springer Open}

supplement market size in 2019 was expected to reach about USD 123.28 billion. The same was projected to increase at a CAGR of $8.2 \%$ during the span of 2020-2027 [4]. Fifty-two million Americans (40\% adults) accounted for use of complementary and alternative medicines reported in the survey of Centers for Disease Control and Prevention USA [5]. A 2011 survey by the Harvard Opinion Research Program revealed that most Americans regularly consume dietary supplements for boosting the immune system [6]. Herbals are considered to be the best option as alternative medicine all around the world due to less cost, easy availability and less side effects as compared 
to synthetic medicines. People should be sure of herbal drugs, owing synthetic drug has adverse effects not only in developed nations but also in developing nations. The consumption of herbal products and food supplements is not reported by people to their physicians or pharmacist. Almost all herbal products are easily available (OTC) in the market. The herbs contain various pharmacological properties due to the presence of multiple chemical constituents. Many times, the label of herbal products contain half-truth or misleading information. Given above are the major factors for HDIs, thereby increasing the likelihood of the HDIs not being identified and resolved in time. Furthermore, clinical trials addressing the safety and risk of coadministered drugs with certain herbal products showed that the outcomes are greatly affected by pharmacogenetics and/or individual.

There is lack of information about use of herbals by patients to physician and pharmacist. Many physicians are unaware about of the possible risks of HDIs. There appears to be dearth of knowledge amongst physician, pharmacist and consumers related to pharmacological action and mechanism of HDIs [7]. As HDIs occur between conventional drugs and herbal products, identification and awareness of exact HDIs become necessary. This review article focuses on the HDIs along with probable mechanisms and clinical manifestation based on case studies reported in the literature.

\section{Method}

To collect all cases of HDIs and adverse effects, a selective literature search using publicly available electronic databases (especially the PubMed database, Scopus, and Korean databases) was performed. We used the search items including "Herbal Drug Interactions", "drug safety pharmacology", "Danshen Interaction", "Echinacea Interactions", "Garlic Interactions", "Ginkgo Biloba Interactions", "Goldenseal Interactions", "Green Tea Interactions", "Kava Interactions", "Liqcorice Interactions", "Milk Thistle Interactions", "St. Jhon's Wort Interactions" alone and combined with the terms "herbal hepatotoxicity", or "herb induced liver injury". The search was primarily focused on English-language case reports, case series and clinical reviews, published till Nov. 2020. The literature with language other than English was used by converting them into English.

\section{Mechanism involved in herb-drug interactions}

Mechanism of HDIs is often clinically significant since it influences both the time course and methods of circumventing the interaction. Different mechanisms of HDIs were reported. It mainly includes the change in the gastrointestinal functions which leads to overall changes in transportation of the drug in the body. The HDI mechanism is broadly classified into pharmacokinetic and pharmacodynamic interactions.

\section{Pharmacokinetic interactions}

Inhibition and induction of transport and efflux proteins The absorption, distribution and elimination of drugs is widely affected by the ATP-binding cassette family which are required for drug transportation.

\section{P-Glycoprotein (P-gp)}

The absorption, distribution and elimination/reabsorption of many clinically important therapeutic substances are regulated by P-gp family proteins. Direct interaction with binding sites on the P-gp molecule takes place through competitive or non-competitive inhibition or induction of the efflux of drugs, due to modulation of P-gp by herbal constituents. The pharmacokinetic interaction based on P-gp occurs mainly by depletion of energy required for driving the translocation of P-gp-bound drug substrate, which takes place due to inhibition of ATP binding, hydrolysis or coupling of ATP-hydrolysed molecules by the phytochemicals present in herbs [8].

\section{Multidrug resistance-associated protein-2 (MRP2)}

MRP2 family is ATP-dependent, which is responsible for the transport of hydrophobic anionic conjugates and extrudes hydrophobic neutral molecules. MRP2 from liver cells exports bulky hydrophilic compounds like glutathione, glucuronide, sulfate conjugates, camptothecin and paracetamol into the bile [9].

Alteration of gastrointestinal functions Alteration of absorption of concomitantly administered medicines along with herbal medicines takes place through several mechanisms: alteration in gastric $\mathrm{pH}$, formation of insoluble complexes due to complexation and chelation, alteration in gastrointestinal motility and alteration in gastrointestinal transit time [10].

Herb-drug interactions at metabolism level The enzymes responsible for the metabolism of synthetic drugs or their transporters are either inhibited or induced by herbal products, which cause HDIs. The enzyme degrades, deactivates or conjugates to drugs before excretion. The inhibition or induction of this enzyme by herbs causes HDIs.

I.Enzyme inhibition The half-lives of drugs can be prolonged by inhibition of drug-metabolizing enzymes. Due to increase in half-lives of drug, plasma concentration of drug may hike unexpectedly after more doses which results into prolonged action or toxicity. Efficacy of drug may be lowered by inhibiting drug transporters, which decreases absorption of therapeutic agents. Inhibition can be of two types, viz. reversible inhibition and irreversible 
inhibition. The systemic exposure of the victim drug due to a decrease in metabolic clearance and/or increase in bioavailability is manifested by reversible inhibition. Competitive inhibition occurs when herb binds to the active sites of the enzyme and prevents the binding of synthetic drug and enzyme $[8,11]$. Irreversible inhibition or quasi-irreversible inhibition is characterised by time-dependent inhibition or mechanism-based inhibition. Irreversible noncovalent binding of an herb to the enzyme takes place in irreversible inhibition. Unlike reversible inhibition, the interaction can continue after removal of the perpetrator since recovery of enzyme activity depends on de novo protein synthesis [12].

II.Enzyme induction Due to enzyme induction, plasma concentration of drug reaches subtherapeutic levels. Toxicity may be due to enhanced blood levels caused by induction of drug transporter. The enzyme induction by herbs may result in a reduction of serum drug concentrations. If metabolite is active, it may result in toxicity [13].

Metabolism occurs in two phases. Phase I reactions involve conversion to a newly formed derivative or cleavage of original drug via oxidation, reduction and hydrolysis reactions. In phase I, P450 enzymes and their subfamilies CYP1A, CYP1B, CYP2C, CYP2D, CYP2E and CYP3A play an important role. These enzymes naturally are present in the liver endoplasmic reticulum and also in the intestine [14]. Phase II reactions involve conjugation with an endogenous substance like glucuronic acid and sulfate. UDP-glucuronosyltransferase and sulfotransferase enzymes catalyse phase II conjugation reaction. Donation of a cofactor through a reaction which is catalysed by transferase causes conjugation of a substrate with a nucleophilic group (amino, hydroxyl, thiol, etc.) [15].

Alteration in renal elimination Herbal products interact with renal functioning, leading to alteration in elimination of drug via inhibition of tubular secretion, tubular reabsorption or interference with glomerular filtration [16]. Certain herbal diuretics increase the glomerular filtration rate, and few act as direct tubular irritants [17].

\section{Pharmacodynamic interactions}

Pharmacodynamic interactions are either additive (or synergetic) or antagonistic. Additive or synergistic interaction potentiates the action of synthetic drug. Antagonistic interaction reduces the efficacy of synthetic drugs [18].

\section{Herbal-drug interactions}

The herbs which were frequently used by physicians and also as home remedies for various ailments in alternative system of medicines are selected for this review.

\section{Danshen (Salvia miltiorrhiza)}

Danshen is used as an antibacterial, antioxidative, antineoplastic, anticoagulation and anti-inflammatory. Danshen contains diterpenoids (tanshinones and royleanones) and phenolic acids including danshensu, caffeic acid, protocatechuic aldehyde, protocatechuic acid, salvianolic acid A -E, lithospermic acid and rosmarinic acid. Danshen also contains essential oils, triterpenoids, flavone, amino acids, metallic elements and many others [19].

Danshen shows haemostasis effects like platelet aggregation inhibition, interference with the extrinsic blood coagulation, antithrombin III-like activity and promotion of fibrinolytic activity. Danshen has reported to increase area under the plasma drug concentration-time curve (AUC), elimination half-lives $\left(t_{1 / 2}\right)$ and maximum plasma concentrations $\left(\mathrm{C}_{\max }\right)$ and decrease total body clearance $(\mathrm{CL})$ and apparent volume of distribution $\left(\mathrm{V}_{\mathrm{d}}\right)$ of $\mathrm{R}$ - and $\mathrm{S}$ - isoform of warfarin in rats. In humans, there was increase in international normalized ratio (INR) after taking danshen and warfarin together [20]. Case report reported interaction between warfarin and danshen, leading to increase in INR, which potentiated anticoagulant effect of warfarin and increased risk of bleeding [21]. Another case was reported which lead to abnormalities of clotting in patient having rheumatic heart disease, caused by danshen and warfarin concomitant use [22].

A sequential pharmacokinetic interaction study reported induction of CYP3A4 enzyme in the gut by danshen. The confidence intervals of $C_{\max }, t_{1 / 2}$, oral clearance $(C L / F)$ and AUC zero to infinity $\left(\mathrm{AUC}_{\infty}\right)$ of midazolam before and after oral administration of danshen tablets were (0.559, 0.849), (0.908, 1.142), (1.086, 1.688) and (0.592, 0.921 ), respectively, was to be $90 \%$. There was a decline in bioavailability of midazolam due to danshen use [23].

\section{Echinacea (Echinacea purpurea)}

Echinacea contains alkamides, caffeic acid derivative, cichoric acid, flavonoids and phenolic acids. Echinacea is worldwide used for its immunomodulatory and antiinflammatory properties. The plant is also reported to show larvicidal activity and antibacterial and antiviral activities, especially against influenza viruses [24].

In in vivo clinical studies, 12 healthy subjects were dosed $1600 \mathrm{mg} /$ day with $\mathrm{E}$. purpurea extracts (for 8 days) along with caffeine, tolbutamide and midazolam to evaluate CYP1A2, CYP2C9 and CYP3A enzyme activities, respectively. The results obtained showed Echinacea extract inhibited hepatic CYP1A2 and CYP2C9, and induced CYP3A4 enzyme activity, which lead to $27 \%$ decrease in caffeine CL/F, $12 \%$ decrease in tolbutamide CL/F and $42 \%$ increase in the systematic clearance and reduced AUC by $23 \%$ of midazolam respectively [25]. Similarly, another in vivo assessment showed that E. purpurea extract inhibited CYP1A2 and induced CYP3A4 [26]. Thus, it is recommended not to use 
drugs that are substrate of CYP1A2, CYP2C9 and CYP3A4 enzyme along with concomitant use of Echinacea extract.

\section{Garlic (Allium sativum)}

Garlic mainly contains organosulfur compounds such as allicin, diallyl disulfide, diallyl trisulfide and S-allyl cysteine. Garlic is used as antihyperlipidemic, antimicrobial, anti-inflammatory, antiprotozoal, anticancer and immunomodulatory activity. Garlic has been reported to show toxicity at higher doses. In contrast, some studies also showed intoxication after consumption of garlic [27].

The two in vivo pharmacokinetic trials were conducted to study the effect of garlic on the antiviral drug saquinavir. The study found that ingestion of garlic increased expression of duodenal P-gp to $131 \%$ in subjects. The average AUC and $\mathrm{C}_{\max }$ of saquinavir was decreased by garlic up to $51 \%$ and $54 \%$ respectively, in subjects with concomitant use along with garlic. The AUC values and $C_{\max }$ values returned up to $60-70 \%$ of their values after the 10-day washout period. Saquinavir is metabolised by the enzyme cytochrome P450 (CYP3A4) and is also a substrate of P-gp. Thus, increased clearance and decreased bioavailability of saquinavir are possible due to induction of P-gp along with concomitant use of garlic [28, 29].

Clinical study shows that the intake of S-allyl cysteine (active constituent of garlic) inhibits platelet aggregation [30]. A human survey found that a significant number of patients who used herbs in conjunction with warfarin had higher INR levels, indicating that this combination had potential or additive effects. Thus, inhibition of platelet aggregation shows an additive anticoagulant effect, which is a possible mechanism for warfarin and garlic interaction, which ultimately increases the anticoagulant effect. Increased anticoagulant may increase the risk of bleeding [31].

The randomized clinical trial of garlic-chlorzoxazone cocktails was given for 28 days on healthy subjects. The pre-supplementation and post-supplementation effect of garlic on CYP2E1 enzyme was evaluated by measuring 6-hydroxychlorzoxazone/chlorzoxazone serum ratio. A controlled trial showed a decrease in 6-hydroxychlorazoxazone/ chlorzoxazone serum ratio by about $22 \%$, which suggests inhibition of CYP2E1 activity by garlic [32]. Similarly, another study showed a $40 \%$ decrease in 6-hydroxychlorzoxazone/ chlorzoxazone serum ratio [33].

A case report showed abnormal INR level in patients using a cocktail of fluindione-garlic. Garlic has been previously reported to inhibit some cytochrome P450 isoforms. Thus, garlic can putatively increase fluindione metabolism, thereby garlic acting as an enzymatic inducer. INR level decreased from 2.4 to 1.8 (post-supplementation of garlic for 12 days), and INR level increased to 2.8 (7 days after stopping garlic). A low INR level reduces the anticoagulant effect, increasing the risk of blood clotting (the cause of stroke). Another mechanism could be inhibition of fluindione binding to plasma proteins, but no such studies have been reported [34]. It is thus suggested that concomitant use of saquinavir, warfarin, chlorzoxazone and fluindione with garlic should be prevented.

\section{Gingko (Ginkgo biloba)}

Ginkgo biloba leaf contains flavonol glycosides (kaempferol, quercetin, myricetin, apigenin, isorhamnetin, luteolin and tamarixetin) and terpene trilactones (ginkgolide A, B, C, J, K, L, M, P, and Q and bilobalide), proanthocyanidins and organic acids. G. biloba leaf extract is used in the treatment of Alzheimer's disease, neurodegenerative disease, cerebral insufficiency, neurosensory problems, eye ailments, vascular insufficiencies, age-related memory deficit and oxidative stress. In addition, G. biloba is leaf used as antiangiogenesis, anti-inflammatory, and anti-asthmatic [35].

In in vivo clinical trials, 10 healthy volunteers were given G. biloba extract (GBE) to test its effect on CYP2C9 using tolbutamide as a probe. The AUC for tolbutamide after taking GBE was reduced by $16 \%$ as compared to AUC before use of garlic along with tolbutamide. Although the interaction is considered minor, caution must be taken during concomitant use [36].

An open-label study in healthy volunteers showed a decrease in the AUC and $\mathrm{C}_{\max }$ of midazolam by $34 \%$ and $31 \%$ respectively when used along with GBE. This research found that GBE induces CYP3A metabolism, which leads to a decrease in midazolam concentrations [37].

In a comparative clinical study, the $C_{\max }$ of nifedipine was nearly doubled in two subjects when GBE was taken at the same time. The probable mechanism of action is inhibition of CYP3A by GBE. Increased nifedipine causes severe and longer-lasting headaches, with dizziness or hot flushes [38].

The human trial reported significantly reduced $\mathrm{C}_{\max }$ of omeprazole (from $0.69 \pm 0.27$ to $0.48 \pm 0.27 \mathrm{mg} / \mathrm{ml}$ ) and omeprazole sulfone (from $0.20 \pm 0.07$ to $0.13 \pm 0.06 \mathrm{mg}$ / $\mathrm{ml}$ ) and an increase in $C_{\max }$ of 5-hydroxyomeprazole (from $0.28 \pm 0.14$ to $0.45 \pm 0.21 \mathrm{mg} / \mathrm{ml}$ ) postadministration of G. biloba with omeprazole. Omeprazole is metabolized to 5-hydroxyomeprazole in the body. Also, after post-administration of G. biloba, renal clearance of 5-hydroxyomeprazole was significantly decreased (from $2.70 \pm 1.17$ to $1.53 \pm 0.79 \mathrm{~mL} / \mathrm{min} / \mathrm{kg}$ ). The mechanism for this interaction is increased hydroxylation of omeprazole by induction of CYP2C19 [39].

A single oral dose of GBE did not show any change in the pharmacokinetics of talinolol in 10 healthy, nonsmoking male volunteers. $C_{\max }$ of talinolol was raised by $36 \%$, AUC (0-24) by $26 \%$ and $\mathrm{AUC}_{\infty}$ by $22 \%$ respectively. A study suggests that long-term use of GBE prejudiced talinolol disposition in humans, by affecting the activity of drug transporters like P-gp [40].

Randomized controlled trials showed elevation in AUC and $\mathrm{C}_{\max }$ of fexofenadine by $55 \%$ and $68 \%$ respectively. 
Probable mechanism for this is inhibition of P-gp-mediated efflux in humans by GBE. The AUC and $\mathrm{C}_{\max }$ of fexofenadine were expressively increased after coadministration quercetin (constituent of gingko) as compared to that of the placebo treatment.

A case report suggested that fatal cerebral haemorrhage was associated with concomitant use of G. biloba and ibuprofen intake in healthy men. Potential inhibition of platelet-activating factor takes place due to ginkgolide B that is a component of G. biloba. G. biloba has been reported with bleeding complications. The interaction takes place possibly due to the additive effect of GBE on ibuprofen by the inhibition of the TXA2-dependent platelet aggregation [41].

A case study showed that there was an increase in BP in a man, with coadministration of thiazide diuretics and GBE. The blood pressure increased further for a few weeks. BP returned to normal level when both diuretics and GBE were stopped. Due to the severity of complication of the interaction, the responses were not rechallenged. Diuretics are known to lower the BP, but use of GBE leads to the opposite pharmacodynamic effect (increased blood pressure). The possible mechanism for this interaction could be agonism. There are no clinical trials recorded for increase in blood pressure by GBE, but the combination should be prevented [42].

In a case study, fatal seizures were reported with anticonvulsant medications like valproic acid. GBE has been reported to induce CYP2C19 enzyme activity. The CYP450 enzyme is reported to metabolise valproate, chiefly by CYP2C9 and CYP2C19. Thus, this coadministration of valproic acid and Ginkgo biloba extract should be prevented [43].

A case study reported that a man with a persistent and painful erection of the penis that had lasted for $4 \mathrm{~h}$ was admitted to a hospital. Metabolism of risperidone by CYP2D6 and CYP3A4 has been recorded in literature. Both the enzymes CYP2D6 and CYP3A4 are inhibited by GBE, which is a mechanism or interaction between risperidone and GBE. Simultaneous use of GBE and risperidone increases the serum concentration of risperidone and increases the hazard of adverse effects, such as priapism [44].

Negative pharmacokinetic interaction of efavirenz was reported, in a case study (47-year-old HIV infected patient), with terpenoids (component of G. biloba). The probable mechanism of interaction was either by induction of CYP3A4 and P-gp. Induction of CYP3A4 and P-gp by terpenoids lowers the efavirenz plasma level in patients (from 1.26 to $0.48 \mathrm{mg} / \mathrm{l})$. The lowering of human plasma efavirenz level results in virological failure. So, it is recommended that the combination should be avoided [45].

Flavonoids are a component of G. biloba bound to benzodiazepine binding site, which possess GABAergic activity. Trazadone is used to treat behavioural disturbances as it possesses hypnotic and sedative activity. The CYP3A4 enzyme is responsible for metabolism of trazodone into active compound 1-(m-chlorophenyl) piperazine (mCPP). Flavonoids increase the activity of CYP3A4 in humans. A case study reported that flavonoids act on benzodiazepine receptors and increase the GABAergic activity by increasing $\mathrm{mCPP}$ production (mCPP enhances the release of GABA), which leads to increased GABAergic activity and leads to coma in patients [46].

\section{Goldenseal (Hydrastis canadensis)}

Goldenseal mainly contains berberine, 3,4-dimethoxy-2(methoxycarbonyl) benzoic acid, 3,5,30 -trihydroxy-7,40 -dimethoxy-6,8-C-dimethyl-flavone, chilenine, (2R)-5,40 -dihydroxy-6-C-methyl -7-methoxy-flavanone, 5,40 -dihydroxy6,8-di-C-methyl-7-methoxy-flavanone, noroxyhydrastinine, oxyhydrastinine and 40,50-dimethoxy-4-methyl-30-oxo-(1,2, 5,6-tetrahydro-4H-1,3-dioxolo-[40,50:4,5] -benzo [1,2-e]-1, 2-oxazocin)-2-spiro-10-phtalan [47]. Goldenseal is reported in folk medicine for the treatment of urinary disorders, gastrointestinal disturbances and skin ailments [48].

In vivo clinical study was performed for the action of goldenseal on CYP isoform enzyme, which reported inhibition of CYP2D6 and CYP3A4/5 by 40\% [49].

A study on humans was performed to determine CYP2D6 activity using debrisoquine. By evaluating debrisoquine urinary recovery ratios, $50 \%$ inhibition of CYP2D6 activity was observed by post-supplementation of goldenseal along with debrisoquine, which lead to a decrease in debrisoquine urinary recovery ratios [50].

Randomized clinical trials in healthy humans showed that $\mathrm{AUC}_{\infty}$ and $\mathrm{C}_{\max }$ increased from $107.9 \pm 43.3$ to $175.3 \pm 74.8 \mathrm{ng} . \mathrm{h} / \mathrm{ml}$ and from $50.6 \pm 26.9$ to $71.2 \pm 50.5$ $\mathrm{ng} / \mathrm{ml}$ respectively for midazolam, with concomitant use of goldenseal. AUC and $\mathrm{C}_{\max }$ of midazolam were increased by inhibition of CYP3A4/5 [51].

Berberine is a chemical found in goldenseal extract. A clinical trial was performed on humans to check the effect of berberine on pharmacokinetics of cyclosporin A. The results obtained from this trial showed an increase in AUC of cyclosporin A from 104 to $123 \mathrm{mg} / \mathrm{l}$. This study proves berberine mediated increase in cyclosporin A bioavailability by inhibition of CYP3A4 [52].

\section{Green tea (Camellia sinensis)}

Green tea mainly contains catechins, polyphenols and epigallocatechin-3-gallate. Green tea possesses antioxidant, antimutagenic, antidiabetic, anti-inflammatory, antibacterial and antiviral properties. Green tea is used for weight loss and preventing ageing and prostate and other cancers [53].

An in vivo study reported that catechins (present in green tea extract) inhibit folic acid uptake. Catechins are competitive inhibitors of DHFR, which adversely affect folate uptake. DHFR is responsible for folate intestinal 
absorption. Folate is reduced to tetrahydrofolate and methylated to 5-methyltetrahydrofolate during intestinal absorption of folate before it is absorbed in the blood [54]. In vivo studies in humans reported reduction in $\mathrm{C}_{\max }$ and AUC of folic acid by $58.4 \%$ and $43.9 \%$, during concomitant use of folic acid and green tea, leading to a decrease in bioavailability of folic acid. The probable mechanism of interaction is inhibition of carriermediated absorption of folates [55].

A clinical trial in humans reported that green tea weakly inhibits CYP450 3A4, which is the main metabolizing enzyme of simvastatin [56]. A study showed that consumption of green tea with simvastatin leads to increase in $\mathrm{C}_{\max }$ of simvastatin lactone (metabolite of simvastatin lactone prodrug) from 3.70 to $7.21 \mathrm{ng} / \mathrm{mL}$, before and after supplementation of green tea. Similarly, the AUC of simvastatin lactone increased from 6.3 to $12.5 \mathrm{ng} . \mathrm{h} / \mathrm{mL}$. The subject improved tolerance to simvastatin after the patient stopped drinking green tea and simvastatin [57].

Green tea is a source of vitamin K [58]. Green tea products accentuate the anticoagulant effect of warfarin, leading to bleeding complications. Exogenous intake of vitamin $\mathrm{K}$ antagonises the effect of warfarin. A study on humans showed a decrease in INR level from 3.79 to 1.14 (after 1 month) on concomitant consumption of green tea and warfarin. The INR level increased to 2.55 on the discontinuation of green tea [59].

\section{Kava (Piper methysticum)}

Kava contains kavain, dihydrokavain, methysticin, dihydromethysticin, demethoxyyangonin, and yangonin. Kava has a beneficial effect in euphoria, analgesia, neuroprotection, and anticonvulsant properties. Kava is also used in the treatment of anxiety [60].

The active components of kava (pyrones) are reported to have neuropharmacologic interactions with the central nervous system receptors. Kava also has weak effects on GABA or benzodiazepine receptors [61]. A study showed additive pharmacodynamic effects between a-pyrones and other GABA-active sedatives [62]. A case study showed a lethargic and disoriented state in patients during concomitant use of kava and alprazolam (benzodiazepine) [63]. Previous studies showed that this interaction is possible due to the additive effect of kava on benzodiazepine receptors, leading to life-threatening conditions.

Kava inhibits CYP2E1, and chlorzoxazone is a CYP2E1 probe. Clinical trials reported that kava showed a significant reduction in 6-hydroxychlorzoxazone/chlorzoxazone serum ratios by $40 \%$. It is, thus, suggested that kava should not be taken simultaneously with chlorzoxazone [49].

Kava is reported to have dopamine antagonism property. A case report in a 76-year-old Parkinson's disease patient showed reduced activity of levodopa (a precursor of dopamine). On further investigation, it was reported that the patient simultaneously consumed kava and dopamine, which lead to decrease in dopamine efficacy (decreased dopamine level) due to an antagonising property of kava [64].

\section{Liquorice (Glycyrrhiza glabra)}

Biologically active compounds present in liquorice are glycosides (glycyrrhizic acid), flavonoids (chalcones, liquiritin, isoliquiritin, liquiritin apioside and isoprenoid-substituted flavonoids), chromenes (coumarins and dihydrostilbenes) and saponins (triterpenoid saponins). Liquorice is reported for wide-ranging biological activities like antiviral, antimicrobial, antioxidant, antiallergic, hepatoprotective, neuroprotective, anti-inflammatory and dermatological activities [65].

Glycyrrhizin is a potent inducer of the CYP3A4metabolizing enzyme. CYP3A4 catalyses sulfoxidation of omeprazole. A study reported that glycyrrhizin induces CYP3A4-catalysed sulfoxidation of omeprazole leading to a decrease in $\mathrm{C}_{\max }$ of omeprazole, during simultaneous use of liquorice and omeprazole [66].

Glycyrrhizin induces CYP3A4 enzyme (which catalyses midazolam 11-hydroxylation), leading to a reduction in plasma concentrations of midazolam. This inhibition was confirmed by an in vivo study, where mRNA expression of CYP3A4 and other CYP450 family members in mice was decreased significantly by liquorice. Human study confirmed an interaction between midazolam and liquorice [67].

\section{Milk thistle (Silybum marianum)}

Silybin A and B, isosilybin A and B, silychristin A, silyhermin, neosilyhermine $A$, neosilyhermine $B$, mariamides $A$ and $\mathrm{B}$, quercetin, morin, chlorogenic acid and caffeic acid are some of the major chemical constituents present in milk thistle. Milk thistle is widely used in jaundice and calculi of the liver and gallbladder and is useful in controlling haemorrhages [68].

Metronidazole is a substrate of CYP3A4-metabolizing enzyme. A clinical trial on 12 human subjects confirmed increased CL of metronidazole (by 29.51\%) with concomitant use of milk thistle. It also decreased $t^{1} / 2, C_{\max }$ and AUC, as a cause of induction of both intestinal P-gp and CYP3A4 [69].

Milk thistle decreased the AUC of E-3174 (active metabolite of losartan) and increased the AUC of losartan, reported in a clinical trial on 12 healthy men. The study reported that the decrease in losartan AUC is dependent on inhibition of CYP2C9 [70].

Talinolol $\mathrm{C}_{\max }$ increased potentially from $172.68 \pm$ 61.53 to $219.20 \pm 52.77 \mathrm{ng} / \mathrm{ml}$ (after 14 days) after simultaneous administration of milk thistle as compared to placebo treatment, in human studies. AUC of talinolol increased by $36.2 \%$, and oral clearance of talinolol decreased by $23.1 \%$ during milk thistle-talinolol coadministration, by inhibition of P-gp [71]. 


\section{St. John's wort (Hypericum perforatum)}

The major active constituents present in St. John's wort are hyperforin and hypericin (pseudohypericin, isohypericin, protohypericin, protopseudohypericin, Cyclopseudohypericin) and also flavonoids (kaempferol, quercetin, luteolin, biapigenin), tannins and volatile oils. St. John's wort is used as an antidepressant, antiviral and antibacterial. It also shows sedative and astringent properties. It is used traditionally for the treatment of excitability, neuralgia, sciatica, fibrositis, anxiety, menopausal neurosis and depression and as a nerve tonic and topical application for wound treatment [72].

The study confirmed that long-term use of SJW may cause reduced clinical effectiveness of CPY3A4 substrate drugs by CPY3A4 induction, which may lead to an increase in dosage of the drug [73]. The study showed direct induction of intestinal P-gp/MDR1 by SJW in humans [74].

CYP2C19 carries out demethylation of amitriptyline to nortriptyline, at low amitriptyline concentration. When the concentration of amitriptyline is higher, the CYP3A4 enzyme carries out its demethylation [75, 76]. P-gp is a drug transporter which is responsible for efflux of amitriptyline from gut epithelial cells to the gut lumen, which causes co-regulation of systemic availability. Increase activity of P-gp causes reduced systemic availability [77]. A clinical trial showed that concomitant use of amitriptyline and SJW extract LI160 decreases the AUC of amitriptyline (by 22\%) and nortriptyline (by $41 \%$ ), which is a metabolite of amitriptyline in humans. The pharmacokinetics of St. John's wort is affected by induction of CYP3A4 and/or induction of P-gp [78].

Atorvastatin is a substrate of CYP3A4 and P-gp; thus, its use with SJW should be prevented. In a human trial, concomitant treatment with a SJW product reduced the efficacy and effect of atorvastatin, resulting in an increase in LDL cholesterol levels of $0.32 \mathrm{mmol} / \mathrm{l}$, or about $30 \%$ of the expected treatment. The possible mechanism of action is increased in CYP3A4 and P-gp activity [79].

Cyclosporine is widely used to prevent rejection of organs after organ transplantation. Various case reports have reported of serious organ rejection after transplantation due to simultaneous use of cyclosporine with SJW [80-83]. The efficacy of cyclosporine is decreased, which causes rejection of organs [73, 74]. Thus, serious and potentially fatal interactions between cyclosporine and SJW are likely to occur via induction of CYP3A4 and/or P-gp by St. John's wort.

MDR1/P-gp mediates the intestinal absorption and distribution and renal excretion of digoxin. SJW is reported to induce P-gp drug transporter. Clinical trials showed that concomitant use of SJW and digoxin lead to an increase in efflux function of P-gp into the intestinal lumen, which lead to a decrease of digoxin AUC by $25 \%[84,85]$.
A case report on four patients showed a median decrease of $47 \%$ of the original methadone concentration, during concomitant use of methadone and SJW [86].

A study on humans showed a two-fold increase in CL of alprazolam after administration of alprazolam with SJW for 14 days. The increase in $\mathrm{CL}$ of alprazolam was observed due to CYP3A4 enzyme induction. The increased CL leads to a decrease in alprazolam blood concentration [73].

Imatinib is predominantly metabolized by cytochrome CYP3A4. Concomitant use of SJW and imatinib lead to increased imatinib CL by $43 \%$ (12.5 to $17.9 \mathrm{l} / \mathrm{h}$ ), imatinib AUC was decreased by $30 \%$ (from 34.5 to $24.2 \mathrm{mg}$. h/ $\mathrm{ml}$ ) and $\mathrm{C}_{\max }$ was also significantly decreased $[87,88]$.

HIV-1 protease inhibitors are substrates of the CYP3A4 enzyme. A clinical trial was performed to evaluate the effect of SJW on plasma concentrations of the HIV-1 protease inhibitor (indinavir), which was found to decrease plasma levels of indinavir in 8 volunteers by an average of $57 \%$ [89].

A trial performed in 5 cancer patients showed decreased plasma levels of SN-38 (active metabolite of irinotecan) by $42 \%$ on post-supplementation of SJW and irinotecan as compared to the placebo treatment [90].

NNRTI and nevirapine are substrates of multidrug transporter P-gp and are extensively metabolized via the cytochrome CYP3A4 enzyme system. A human study showed a decrease in blood concentration of nevirapine by increasing its oral clearance by $35 \%$, due to induction of CYP3A4 enzyme [91].

In a human subject, it was found that SJW significantly induced the activity of CYP2E1 (approximately 140\%) on comparing pre-supplementation and post-supplementation ratios. The two clinical trials found that SJW extract lead to increase in the hydroxychlorzoxazone/chlorzoxazone serum ratios. This increase in ratio is due to induction of CYP2E1 enzyme [32, 33].

Serotonin reuptake in the central nervous system is inhibited by bupropion [92]. Serotonin reuptake is weakly inhibited by SJW. Various reports of SJW interacting with SSRIs have been reported, leading to various side effects, including serotonin syndrome. The side effect is due to an additive effect of two similarly acting drugs [93]. Dystonia is a syndrome which causes sustained muscle contractions, producing twisting and repetitive movements and postures. Dystonia syndrome is a very well-recognised sideeffect of many medicines (antipsychotics and serotonin reuptake inhibitor drugs) affecting dopamine concentrations. A 58-year-old female reported prolonged orofacial dystonia. On evaluation, it was found that the woman was consuming bupropion and St. John's wort together. Both bupropion and St. John's wort are reported to inhibit the reuptake of dopamine, potentially resulting in additive effects on dopaminergic transmission and hence causing dopaminergic side effects such as dystonia [94]. 
Table 1 Herb-drug interactions (HDIs) of some herbs with possible mechanism, outcome and level of HDls

\begin{tabular}{|c|c|c|c|c|c|}
\hline Herb & Drug & Possible mechanism & HDI outcome & $\begin{array}{l}\text { Level of } \\
\text { HDIS }\end{array}$ & References \\
\hline \multirow[t]{2}{*}{ Danshen } & Warfarin & Additive effect & Potentiated anticoagulant effect & +++ & [19-21] \\
\hline & Midazolam & CYP3A4 induction & Decreased F of midazolam & ++ & [22] \\
\hline \multirow[t]{3}{*}{ Echinacea } & Caffeine & CYP1A2 inhibition & Decreased $\mathrm{CL} / \mathrm{F}$ of caffeine & ++ & {$[24,25]$} \\
\hline & Midazolam & CYP3A4 induction & Increased CL and decreased F of midazolam & + & {$[24,25]$} \\
\hline & Tolbutamide & $\begin{array}{l}\text { CYP2C9 inhibition } \\
\text { (weakly) }\end{array}$ & Reduces CL/F of tolbutamide & + & {$[24,25]$} \\
\hline \multirow[t]{4}{*}{ Garlic } & Saquinavir & P-gp induction & Increased $C L$ and decreased $F$ of saquinavir & +++ & {$[27,28]$} \\
\hline & Warfarin & Additive effect & Increased anticoagulant effect & ++ & {$[29,30]$} \\
\hline & Chlorzoxazone & CYP2E1 inhibition & $\begin{array}{l}\text { Decreased serum 6-hydroxychlorzoxazone/ } \\
\text { chlorzoxazone ratio }\end{array}$ & ++ & {$[31,32]$} \\
\hline & Fluindione & P450 inhibition & Decreased INR level & ++ & [33] \\
\hline \multirow{12}{*}{$\begin{array}{l}\text { Ginkgo } \\
\text { biloba }\end{array}$} & Tolbutamide & CYP2C9 inhibition & Decreased AUC of tolbutamide & + & [35] \\
\hline & Midazolam & CYP3A inhibition & Decreased $A \cup C$ and $C_{\max }$ of midazolam & ++ & {$[36]$} \\
\hline & Nifedipine & CYP3A inhibition & $C_{\max }$ of nifedipine was doubled & +++ & {$[37]$} \\
\hline & Omeprazole & CYP2C19 induction & $\begin{array}{l}\text { Decreased } C_{\max } \text { of omeprazole and increased } C_{\max } \\
\text { of 5-hydroxyomeprazole }\end{array}$ & + & {$[38]$} \\
\hline & Talinolol & P-glycoprotein inhibition & Increased $C_{\max }$ and $A U C$ of talinolol & ++ & [39] \\
\hline & Fexofenadine & $\begin{array}{l}\text { P-gp-mediated efflux } \\
\text { inhibition }\end{array}$ & Increased $A \cup C$ and $C_{\max }$ of fexofenadine & +++ & {$[40]$} \\
\hline & Ibuprofen & Additive effects & Increase anticoagulant effect & +++ & [96] \\
\hline & Diuretic (thiazide) & Agonism & Increased blood pressure & +++ & [41] \\
\hline & Valproic acid & CYP2C19 induction & Fatal seizure & ++ & [42] \\
\hline & $\begin{array}{l}\text { Antipsychotic drug } \\
\text { (risperidone) }\end{array}$ & $\begin{array}{l}\text { CYP2D6 and CYP3A4 } \\
\text { inhibition }\end{array}$ & Increased $C_{\max }$ of risperidone and causes priapism & ++ & [43] \\
\hline & Efavirenz & $\begin{array}{l}\text { CYP3A4 and P-gp } \\
\text { induction }\end{array}$ & $\begin{array}{l}\text { Virologic failure associated with decreased efavirenz } \\
\text { blood concentration }\end{array}$ & ++ & [44] \\
\hline & Trazodone & CYP3A4 induction & $\begin{array}{l}\text { Enhancement of GABAergic activity leading to } \\
\text { coma }\end{array}$ & ++ & [45] \\
\hline \multirow[t]{3}{*}{ Goldenseal } & Debrisoquine & CYP2D6 inhibition & $\begin{array}{l}\text { Decreased debrisoquine urinary recovery ratios } \\
\text { (DURR) }\end{array}$ & +++ & {$[48,49]$} \\
\hline & Midazolam & CYP3A4/5 inhibition & Increased $A \cup C$ and $C_{\max }$ of midazolam & +++ & {$[48,50]$} \\
\hline & Cyclosporin A & CYP3A4 inhibition & Increased blood concentration of cyclosporin A & ++ & {$[48,51]$} \\
\hline \multirow[t]{3}{*}{ Green tea } & Folic acid & $\begin{array}{l}\text { Carrier-mediated } \\
\text { absorption inhibition }\end{array}$ & Decreased $F$ of folic acid & +++ & {$[53,54]$} \\
\hline & Simvastatin & CYP3A4 inhibition & Increased $A \cup C$ and $C_{\max }$ of simvastatin & +++ & {$[55,56]$} \\
\hline & Warfarin & Antagonism effect & Decreased anticoagulant effect & ++ & {$[57,58]$} \\
\hline \multirow[t]{3}{*}{ Kava } & $\begin{array}{l}\text { Benzodiazepine } \\
\text { (Alprazolam) }\end{array}$ & $\begin{array}{l}\text { Additive effect on GABA } \\
\text { receptors }\end{array}$ & Increased benzodiazepine effect & +++ & {$[60-62]$} \\
\hline & Chlorzoxazone & CYP2E1 inhibition & $\begin{array}{l}\text { Decreased 6-hydroxychlorzoxazone/chlorzoxazone } \\
\text { serum ratios }\end{array}$ & +++ & {$[48]$} \\
\hline & Dopamine & Dopamine antagonism & Reduced dopamine efficacy & ++ & [63] \\
\hline \multirow[t]{2}{*}{ Liquorice } & Omeprazole & CYP3A4 induction & Decreased plasma concentrations of omeprazole & ++ & [65] \\
\hline & $\begin{array}{l}\text { Midazolam } \\
\text { (benzodiazepines) }\end{array}$ & CYP3A4 induction & Decreased plasma concentrations of midazolam & ++ & {$[66]$} \\
\hline \multirow[t]{3}{*}{ Milk thistle } & Metronidazole & P-gp \& CYP3A4 induction & Decreased blood concentration of metronidazole & ++ & {$[68]$} \\
\hline & Losartan & CYP2C9 inhibition & Increased AUC of losartan. & ++ & {$[69]$} \\
\hline & Talinolol & P-gp inhibition & $\begin{array}{l}\text { Increased AUC and } C_{\text {max }} \text { and decreased CL/F of } \\
\text { talinolol }\end{array}$ & ++ & [70] \\
\hline
\end{tabular}


Table 1 Herb-drug interactions (HDIs) of some herbs with possible mechanism, outcome and level of HDls (Continued)

\begin{tabular}{|c|c|c|c|c|c|}
\hline Herb & Drug & Possible mechanism & HDI outcome & $\begin{array}{l}\text { Level of } \\
\text { HDIS }\end{array}$ & References \\
\hline \multirow[t]{13}{*}{$\begin{array}{l}\text { St. John's } \\
\text { wort }\end{array}$} & Amitriptyline & $\begin{array}{l}\text { CYP3A4 and P-gp } \\
\text { induction }\end{array}$ & Decreased blood concentration of amitriptyline & ++ & {$[72-77]$} \\
\hline & Atorvastatin & $\begin{array}{l}\text { CYP3A4 and P-gp } \\
\text { induction }\end{array}$ & Reduced efficacy of atorvastatin & + & {$[72,73,78]$} \\
\hline & Cyclosporine & $\begin{array}{l}\text { CYP3A4 and P-gp } \\
\text { induction }\end{array}$ & $\begin{array}{l}\text { Cyclosporine exhibits a relatively small therapeutic } \\
\text { window }\end{array}$ & ++ & $\begin{array}{l}{[72,73,79-} \\
82]\end{array}$ \\
\hline & Digoxin & $\begin{array}{l}\text { CYP3A4 and P-gp } \\
\text { induction }\end{array}$ & Decreased blood concentration of digoxin & ++ & $\begin{array}{l}{[72,73,83,} \\
84]\end{array}$ \\
\hline & Methadone & $\begin{array}{l}\text { CYP3A4 and P-gp } \\
\text { induction }\end{array}$ & Decreased blood concentration of methadone & +++ & {$[72,73,85]$} \\
\hline & Alprazolam & CYP3A4 induction & Decreased blood concentration of alprazolam & +++ & [72] \\
\hline & Imatinib & CYP3A4 induction & Decreased blood concentration of imatinib & +++ & {$[72,86,87]$} \\
\hline & Indinavir & CYP3A4 induction & Decreased blood concentration of indinavir & +++ & {$[72,88]$} \\
\hline & Irinotecan & CYP3A4 induction & Decreased blood levels of SN-38 & +++ & {$[72,89]$} \\
\hline & Nevirapine & CYP3A4 induction & Decreased blood concentration of nevirapine & ++ & {$[72,90]$} \\
\hline & Chlorzoxazone & CYP2E1 induction & $\begin{array}{l}\text { Increase in hydroxylchlorzoxazone/chlorzoxazone } \\
\text { serum ratio }\end{array}$ & ++ & {$[31,32]$} \\
\hline & Bupropion & Additive effects & Orofacial dystonia & +++ & {$[91-94]$} \\
\hline & Buspirone & $\begin{array}{l}\text { Additive effect on } 5-\mathrm{HT} \\
\text { reuptake }\end{array}$ & Hypomanic episode, serotonin syndrome & +++ & [94] \\
\hline
\end{tabular}

P-gp P-glycoprotein, F Bioavailability, AUC area under the plasma drug concentration-time curve, $C_{\text {max }}$ maximum plasma concentrations, $C L$ total renal clearance, $C L / F$ oral clearance

+ Mild HDI

++ Moderate HDI

+++ Major HDI

Buspirone is a partial agonist at 5-HT1A receptors. St. John's wort is testified to be a non-selective 5-HT reuptake inhibitor, which upregulated the postsynaptic 5HT1A and 5-HT2A receptors. A case study reported that the concomitant administration of buspirone and St. John's wort medications leads to overstimulation of the 5HT1A receptors, therefore leading to the development of serotonin syndrome and hypomanic episode [95].

A systematic representation of herb-drug interactions of herbs with possible mechanism, outcome and level of HDIs is given in Table 1.

\section{Conclusion}

Herb-drug interactions may lead to serious side effects. The reviewed studies clearly indicate that herbal medicines can interact with allopathic or modern medicines and show unwanted effects. Most of the interaction may have negligible clinical significance, but some may lead to life-threatening effect on public health. Our review suggests to physician, pharmacist and common people to avoid such combination in practice. Patients should be aware of the herb-drug interactions for their safety. In this review, we have discussed in details herb-drug interaction of most commonly used herbs in a regular practice by physicians all over the world. It is, therefore, important that health care professionals should take into account of herb-drug interactions when prescribing drugs to patients.

\section{Abbreviations}

5-HT: 5-hydroxy tryptamine; ATP: Adenosine triphosphate; AUC: Area under plasma drug concentration-time curve; $A \cup C_{\infty}$ : $A \cup C$ zero to infinity; CAGR: Compound annual growth rate; CL/F: Oral clearance; $\mathrm{CL}$ : Body clearance; $C_{\text {max }}$ : Maximum plasma concentrations; CYP: Cytochrome-P; DHFR: Dihydrofolate reductase; GABA: Gamma-aminobutyric acid; GBE: G. biloba extract; HDIs: Herb-drug interactions; INR: International normalized ratio; mCPP: 1-(m-chlorophenyl) piperazine; MDR: Multidrug resistance; MRP2: Multidrug resistance-associated protein-2; NNRTI: Non-nucleoside reverse transcriptase inhibitors; OTC: Over the counter; P-gp: P-Glycoprotein; SJW: St. John's wort; $t_{1 / 2}$ : Elimination half-lives; TXA2: Thromboxane A2; UDP: Uridine diphosphate; USD: United States dollar; $V_{d}$ : Apparent volume of distribution

\section{Acknowledgements}

Authors are also thankful to the Principal, S.M.B.T. College of Pharmacy, Dhamangaon, India, for providing necessary facilities.

\section{Authors' contributions}

SAP and SBG collected the reference material and prepared the draft of manuscript. ARS and MRK conceptualized, designed, and concluded the work and prepared the final version for submission. The authors read and approved the final manuscript.

Funding

No funding was available for this work.

Availability of data and materials

Not applicable 


\section{Declarations}

Ethics approval and consent to participate

Not applicable

\section{Consent for publication}

Not applicable

\section{Competing interests}

The authors declare that they have no competing interests.

\section{Received: 15 January 2021 Accepted: 10 May 2021}

Published online: 20 May 2021

\section{References}

1. Williamson E, Driver S, Baxter K (2002) Stockley's herbal medicines interactions, 6th ed. pharmaceutical press, London.

2. Pasi AK (2013) Herb-drug interaction: an overview. Int J Pharm Sci Res 4: 3770-3774. https://doi.org/https://doi.org/10.13040/IJPSR.0975-8232.4(10).3 770-74

3. Izzo AA, Borrelli F, Capasso R (2002) Herbal medicine: the dangers of drug interaction. Trends Pharmacol Sci 23(8):358-359. https://doi.org/10.1016/s01 65-6147(02)02059-x

4. (2021) Dietary Supplements Market Size | Industry Analysis Report 2027 Dietary supplements market size, share \& trends analysis report by ingredient (vitamins, minerals), by form, by application, by end user, by distribution channel, by region, and segment forecasts, 2020 - 2027.

5. Barnes PM, Bloom B, Nahin RL (2008) Complementary and alternative medicine use among adults and children: United States, 2007. Natl Health Stat Report 12:1-23

6. Blendon RJ, Benson JM, Botta MD, Weldon KJ (2013) Users' views of dietary supplements. JAMA Intern Med 173 1:74-76. https://doi.org/https://doi. org/10.1001/2013.jamainternmed.311.

7. Fasinu PS, Bouic PJ, Rosenkranz B (2012) An Overview of the Evidence and Mechanisms of Herb-Drug Interactions. Front Pharmacol 3:1-19. https://doi. org/https://doi.org/10.3389/fphar.2012.00069

8. Lin JH, Lu AYH (1998) Inhibition and induction of cytochrome P450 and the clinical implications. Clin Pharmacokinet 35 5:361-390. https://doi.org/ https://doi.org/10.2165/00003088-199835050-00003.

9. Takano M, Yumoto R, Murakami T (2006) Expression and function of efflux drug transporters in the intestine. Pharmacol Ther 109 1-2:137-161. https:// doi.org/https://doi.org/10.1016/j.pharmthera.2005.06.005.

10. Fugh-Berman A (2000) Herb-drug interactions. Lancet 355 9198:134-138. https://doi.org/https://doi.org/10.1016/S0140-6736(99)06457-0.

11. Hollenberg PF (2002) Characteristics and common properties of inhibitors, inducers, and activators of CYP enzymes. Drug Metab Rev 34 1-2:17-35. https://doi.org/https://doi.org/10.1081/DMR-120001387.

12. Grimm SW, Einolf HJ, Hall SD, He K, Lim HK, Ling KHJ, Lu C, Nomeir AA, Seibert E, Skordos KW, Tonn GR, Van Horn R, Wang RW, Wong YN, Yang TJ, Obach RS (2009) The conduct of in vitro studies to address time-dependent inhibition of drug-metabolizing enzymes: a perspective of the pharmaceutical research and manufacturers of America. Drug Metab Dispos 37 7:1355-1370. https://doi.org/https://doi.org/10.1124/dmd.109.026716.

13. Wienkers LC, Heath TG (2005) Predicting in vivo drug interactions from in vitro drug discovery data. Nat Rev Drug Discov 4 10:825-833. https://doi. org/https://doi.org/10.1038/nrd1851.

14. Ortiz de Montellano PR (1995) Cytochrome P450: structure, mechanism, and biochemistry, 2nd edn. Kluwer Academic / Plenum Press, New York. https:// doi.org/10.1007/978-1-4757-2391-5

15. Tsai HH, Lin HW, Simon Pickard A, Tsai HY, Mahady GB (2012) Evaluation of documented drug interactions and contraindications associated with herbs and dietary supplements: a systematic literature review. Int J Clin Pract 66 11:1056-1078. https://doi.org/https://doi.org/1 0.1111/j.1742-1241.2012.03008.x

16. Bagnis Cl, Deray G, Baumelou A, Le Quintrec M, Vanherweghem JL (2004) Herbs and the kidney. Am J Kidney Dis 44 1:1-11. https://doi.org/https://doi. org/10.1053/j.ajkd.2004.02.009

17. Al-Ali M, Wahbi S, Twaij H, Al-Badr A (2003) Tribulus terrestris: preliminary study of its diuretic and contractile effects and comparison with Zea mays. J Ethnopharmacol 85 2-3:257-260. https://doi.org/https://doi.org/10.1016/S03 78-8741(03)00014-X
18. Izzo AA (2005) Herb-drug interactions: an overview of the clinical evidence. Fundam Clin Pharmacol 19 1:1-16. https://doi.org/https://doi.org/10.1111/ j.1472-8206.2004.00301.x

19. MElm XD, Cao YF, Che YY, Li J, Shang ZP, Zhao WJ, Qiao YJ, Zhang JY (2019) Danshen: a phytochemical and pharmacological overview. Chin J Nat Med 17 1:59-80. https://doi.org/https://doi.org/10.1016/S1875-5364 (19)30010-X

20. Chan TYK (2001) Interaction between warfarin and danshen (salvia miltiorrhiza). Ann Pharmacother 35 4:501-504. https://doi.org/https://doi. org/10.1345/aph.19029

21. Izzat MB, Yim APC, El-Zufari MH (1998) A taste of Chinese medicine! Ann Thorac Surg 66 3:941-942. https://doi.org/https://doi.org/10.1016/S0003-4 975(98)00624-9

22. Yu CM, Chan JCN, Sanderson JE (1997) Chinese herbs and warfarin potentiation by "Danshen." J Intern Med 241:337-339. https://doi.org/ https://doi.org/10.1046/j.1365-2796.1997.134137000.x

23. Qiu F, Wang G, Zhang R, Sun J, Jiang J, Ma Y (2010) Effect of danshen extract on the activity of CYP3A4 in healthy volunteers. Br J Clin Pharmacol 69 6:656-662. https://doi.org/https://doi.org/10.1111/j.13 65-2125.2010.03624.x

24. Manayi A, Vazirian M, Saeidnia S (2015) Echinacea purpurea: pharmacology, phytochemistry and analysis methods. Pharmacogn Rev 9 17:63-72. https:// doi.org/https://doi.org/10.4103/0973-7847.156353

25. Gorski JC, Huang S-M, Pinto A, Hamman MA, Hilligoss JK, Zaheer NA, Desai M, Miller M, Hall SD (2004) The effect of echinacea (Echinacea purpurea root) on cytochrome P450 activity in vivo. Clin Pharmacol Ther 75 1:89-100. https://doi.org/https://doi.org/10.1016/j.clpt.2003.09.013

26. Gurley B, Gardner S, Hubbard M, Williams D, Gentry W, Carrier J, Khan I, Edwards D, SHAH AB, Gurley B, Gardner S, Hubbard M, Williams D, Gentry W, Carrier J, Khan I, Edwards D, Shah A (2004) In vivo assessment of botanical supplementation on human cytochrome P450 phenotypes: Citrus aurantium, Echinacea purpurea, milk thistle, and saw palmetto. Clin Pharmacol Ther 76: 428-440. https://doi.org/https://doi.org/10.1016/j.clpt.2004.07.007

27. Mikaili P, Maadirad S, Moloudizargari M, Aghajanshakeri S, Sarahroodi S (2013) Therapeutic uses and pharmacological properties of garlic, shallot, and their biologically active compounds. Iran J Basic Med Sci 16:1031-1048. https://doi.org/https://doi.org/10.22038/ijbms.2013.1865, 10

28. Hajda J, Rentsch KM, Gubler C, Steinert H, Stieger B, Fattinger K (2010) Garlic extract induces intestinal P-glycoprotein, but exhibits no effect on intestinal and hepatic CYP3A4 in humans. Eur J Pharm Sci 41:729-735. https://doi.org/ https://doi.org/10.1016/j.ejps.2010.09.016, 5

29. Piscitelli SC, Burstein AH, Welden N, Gallicano KD, Falloon J (2002) The effect of garlic supplements on the pharmacokinetics of saquinavir. Clin Infect Dis 34 2:234-238. https://doi.org/https://doi.org/10.1086/324351

30. Macan H, Uykimpang R, Alconcel M, Takasu J, Razon R, Amagase H, Niihara Y (2006) Aged garlic extract may be safe for patients on warfarin therapy. J Nutr 136 3:793S-795S. https://doi.org/https://doi.org/10.1093/jn/136.3.793s

31. Djuv A, Nilsen OG, Steinsbekk A (2013) The co-use of conventional drugs and herbs among patients in Norwegian general practice: a cross-sectional study. BMC Complement Altern Med 13 1:1-11. https://doi.org/https://doi. org/10.1186/1472-6882-13-295

32. Gurley B, Gardner S, Hubbard M, Williams D, Gentry W, Khan I, Shah A (2005) Clinical assessment of effects of botanical supplementation on cytochrome P450 phenotypes in the elderly: St John's wort, garlic oil, Panax ginseng and Ginkgo biloba. Drugs Aging 22 6:525-539. https://doi.org/ https://doi.org/10.2165/00002512-200522060-00006

33. Gurley BJ, Gardner SF, Hubbard MA, Williams DK, Gentry WB, Cui Y, Ang CYW (2002) Cytochrome P450 phenotypic ratios for predicting herb-drug interactions in humans. Clin Pharmacol Ther 72 3:276-287. https://doi.org/ https://doi.org/10.1067/mcp.2002.126913

34. Pathak A, Léger P, Bagheri H, Senard JM, Boccalon H, Montastruc JL (2003) Garlic interaction with fluindione: a case report. Therapies 58 4:380-381. https://doi.org/https://doi.org/10.2515/therapie:2003060

35. Mohanta TK, Tamboli Y, Zubaidha PK (2014) Phytochemical and medicinal importance of Ginkgo biloba L. Nat Prod Res 28 10:746-752. https://doi.org/ https://doi.org/10.1080/14786419.2013.879303

36. Uchida S, Yamada H, Li XD, Maruyama S, Ohmori Y, Oki T, Watanabe H, Umegaki K, Ohashi K, Yamada S (2006) Effects of Ginkgo biloba extract on pharmacokinetics and pharmacodynamics of tolbutamide and midazolam in healthy volunteers. J Clin Pharmacol 46 11:1290-1298. https://doi.org/ https://doi.org/10.1177/0091270006292628 
37. Robertson SM, Davey RT, Voell J, Formentini E, Alfaro RM, Penzak SR (2008) Effect of Ginkgo biloba extract on lopinavir, midazolam and fexofenadine pharmacokinetics in healthy subjects. Curr Med Res Opin 24:591-599. https://doi.org/https://doi.org/10.1185/030079908X260871, 2

38. Yoshioka M, Ohnishi N, Koishi T, Obata Y, Nakagawa M, Matsumoto T, Tagagi K, Takara K, Ohkuni T, Yokoyama T, Kuroda K (2004) Studies on interactions between functional foods or dietary supplements and medicines. IV. Effects of Ginkgo biloba leaf extract on the pharmacokinetics and pharmacodynamics of nifedipine in healthy volunteers. Biol Pharm Bull 27 12:2006-2009. https://doi.org/https://doi.org/10.1248/bpb.27.2006

39. Ophelia Y, Brian T, Mary W, Albert C, Mosess C (2004) Pharmacogenetics and herb-drug interactions: experience with Ginkgo biloba and omeprazole. Pharmacogenetics 14:841-850

40. Fan L, Tao GY, Wang G, Chen Y, Zhang W, He YJ, Li Q, Lei HP, Jiang F, Hu DL, Huang YF, Zhou HH (2009) Effects of Ginkgo biloba extract ingestion on the pharmacokinetics of talinolol in healthy Chinese volunteers. Ann Pharmacother 43 5:944-949. https://doi.org/https://doi. org/10.1345/aph.1L656

41. Meisel C, Johne A, Roots I (2003) Fatal intracerebral mass bleeding associated with Ginkgo biloba and ibuprofen. Atherosclerosis 167 2:367. https://doi.org/https://doi.org/10.1016/S0021-9150(03)00015-7

42. Shaw D, Leon C, Kolev S, Murray V (1997) Traditional remedies and food supplements. A 5-year toxicological study (1991-1995). Drug Saf 17 5:342356. https://doi.org/https://doi.org/10.2165/00002018-199717050-00006

43. Kupiec T, Raj V (2005) Fatal seizures due to potential herb-drug interactions with Ginkgo biloba. J Anal Toxicol 29 7:755-758. https://doi.org/https://doi. org/10.1093/jat/29.7.755

44. Lin YY, Chu SJ, Tsai SH (2007) Association between priapism and concurrent use of risperidone and Ginkgo biloba . Mayo Clin Proc 82 10:1289-1290. https://doi.org/https://doi.org/10.4065/82.10.1289

45. Wiegman D-J, Brinkman K, Franssen EJ (2009) Interaction of Ginkgo biloba with efavirenz. AIDS 23 9:1184-1185. https://doi.org/https://doi.org/10.1097/ QAD.0b013e32832c412b

46. Galluzzi S, Zanetti O, Binetti G, Trabucchi M, Frisoni G (2000) Coma in a patient with Alzheimer's disease taking low dose trazodone and ginkgo biloba. J Neurol Neurosurg Psychiatry 68:679-6680. https://doi.org/https:// doi.org/10.1136/jnnp.68.5.679a

47. Leyte-Lugo M, Britton ER, Foil DH, Brown AR, Todd DA, Rivera-Chávez J, Oberlies NH, Cech NB (2017) Secondary metabolites from the leaves of the medicinal plant goldenseal (Hydrastis canadensis). Phytochem Lett 20:5460. https://doi.org/https://doi.org/10.1016/j.phytol.2017.03.012

48. Ernst $E$ (2006) Complementary therapies for pain management: an evidence-based approach, 2nd edn. Mosby Elsevier, Philadelphia

49. Gurley B, Gardner S, Hubbard M, Williams D, Gentry W, Khan I, Shah A (2005) In vivo effects of goldenseal, kava kava, black cohosh, and valerian on human cytochrome P450 1A2, 2D6, 2E1, and 3A4/5 phenotypes. Clin Pharmacol Ther 77:415-426. https://doi.org/https://doi.org/10.1016/j.clpt.2 005.01.009, 5

50. Gurley BJ, Swain A, Hubbard MA, Williams DK, Barone G, Hartsfield F, Tong Y, Carrier DJ, Cheboyina S, Battu SK (2008) Clinical assessment of CYP2D6mediated herb-drug interactions in humans: effects of milk thistle, black cohosh, goldenseal, kava kava, St. John's wort, and Echinacea. Mol Nutr Food Res 52(7):755-763. https://doi.org/https://doi.org/10.1002/mnfr.200600300

51. Gurley B, Swain A, Hubbard M, Hartsfield F, Thaden J, Williams DK, Gentry WB, Tong Y (2008) Supplementation with goldenseal (Hydrastis canadensis), but not kava kava (Piper methysticum), inhibits human CYP3A activity in vivo. Clin Pharmacol Ther 83(1):61-69. https://doi.org/https://doi.org/10.1 038/sj.clpt.6100222

52. Xin HW, Wu XC, Li Q, Yu AR, Zhong MY, Liu YY (2006) The effects of berberine on the pharmacokinetics of ciclosporin a in healthy volunteers. Methods Find Exp Clin Pharmacol 28(1):25-29. https://doi.org/https://doi. org/10.1358/mf.2006.28.1.962774

53. Rani R, Nagpal D, Gullaiya S, Madan S, Agrawal S (2014) Phytochemical, pharmacological and beneficial effects of green tea. Artic Int J Pharmacogn Phytochem Res 6:420-426

54. Alemdaroglu NC, Wolffram S, Biossel J-P, Closs E, Spahn-Langguth H, Langguth P (2007) Inhibition of folic acid uptake by catechins and tea extracts in Caco-2 cells. Planta Med 73(01):27-32. https://doi.org/https://doi. org/https://doi.org/10.1055/s-2006-951745

55. Alemdaroglu NC, Dietz U, Wolffram S, Spahn-Langguth $H$, Langguth $P$ (2008) Influence of green and black tea on folic acid pharmacokinetics in healthy volunteers: potential risk of diminished folic acid bioavailability. Biopharm Drug Dispos 29(6):335-348. https://doi.org/https://doi.org/10.1 002/bdd.617

56. Chow HHS, Hakim IA, Vining DR, Crowell JA, Cordova CA, Chew WM, Xu MJ, Hsu CH, Ranger-Moore J, Alberts DS (2006) Effects of repeated green tea catechin administration on human cytochrome P450 activity. Cancer Epidemiol Biomark Prev 15(12):2473-2476. https://doi.org/https://doi.org/1 0.1158/1055-9965.EPI-06-0365

57. Werba JP, Giroli M, Cavalca V, Nava MC, Tremoli E, Bo LD (2008) The effect of green tea on simvastatin tolerability. Ann Intern Med 149:286-287. https://doi.org/https://doi.org/10.7326/0003-4819-149-4-200808190-00019, 4

58. Booth SL, Sadowski JA, Pennington JAT (1995) Phylloquinone (vitamin K1) content of foods in the U.S. Food and Drug Administration's Total diet study. J Agric Food Chem 43(6):1574-1579. https://doi.org/https://doi.org/1 $0.1021 / \mathrm{jf0} 0054 \mathrm{a} 030$

59. Taylor JR, Wilt VM (1999) Probable antagonism of warfarin by green tea. Ann Pharmacother 33(4):426-428. https://doi.org/https://doi.org/10.1345/aph.18238

60. Cote CS, Kor C, Cohen J, Auclair K (2004) Composition and biological activity of traditional and commercial kava extracts. Biochem Biophys Res Commun 322(1):147-152. https://doi.org/https:/doi.org/10.1016/j.bbrc.2004.07.093

61. Davies LP, Drew CA, Duffield P, Johnston GAR, Jamieson DD (1992) Kava pyrones and resin: studies on GABAA, GABAB and benzodiazepine binding sites in rodent brain. Pharmacol Toxicol 71(2):120-126. https://doi.org/ https://doi.org/10.1111/j.1600-0773.1992.tb00530.x

62. Jussofie A, Schmiz A, Hiemke C (1994) Kavapyrone enriched extract from Piper methysticum as modulator of the GABA binding site in different regions of rat brain. Psychopharmacology 116(4):469-474. https://doi.org/ https://doi.org/10.1007/BF02247480

63. Almeida JC, Grimsley EW (1996) Coma from the health food store: interaction between kava and alprazolam. Ann Intern Med 125(11):940-941. https://doi.org/https://doi.org/10.7326/0003-4819-125-11-199612010-00023

64. Schelosky L, Raffauf C, Jendroska K, Poewe W (1995) Kava and dopamine antagonism. J Neurol Neurosurg Psychiatry 58(5):639-640. https://doi.org/1 0.1136/jnnp.58.5.639

65. Mamedov NA, Egamberdieva D (2019) Phytochemical constituents and pharmacological effects of licorice: a review. In: Ozturk M, Hakeem KR (eds) Plant and human health, Pharmacology and therapeutics uses, vol 3. Springer, Switzerland, pp 1-21

66. Tu JH, Hu DL, Dai LL, Sun Y, Fan L, Zhang M, Tan ZR, Chen Y, Li Z, Zhou HH (2010) Effect of glycyrrhizin on CYP2C19 and CYP3A4 activity in healthy volunteers with different CYP2C19 genotypes. Xenobiotica 40(6):393-399. https://doi.org/https://doi.org/10.3109/00498251003748095

67. Lv Q-L, Wang G-H, Chen S-H, Hu L, Zhang X, Ying G, Qin C-Z, Zhou H-H (2016) In vitro and in vivo inhibitory effects of glycyrrhetinic acid in mice and human cytochrome P450 3A4. Int J Environ Res Public Health 13(1):84. https://doi.org/https://doi.org/10.3390/ijerph13010084

68. Porwal O, Mohammed Ameen MS, Anwer ET, Uthirapathy S, Ahamad J, Tahsin A (2019) Silybum marianum (Milk Thistle): review on its chemistry, morphology, ethnomedical uses, phytochemistry and pharmacological activities. J Drug Deliv Ther 9: 5199-206. https://doi.org/https://doi.org/1 0.22270/jddt.v9i5.3666

69. Rajnarayana K, Reddy M, Vidyasagar J, Krishna D (2004) Study on the influence of silymarin pretreatment on metabolism and disposition of metronidazole. Arzneimittelforschung 54(02):109-113. https://doi.org/ https://doi.org/10.1055/s-0031-1296944

70. Han Y, Guo D, Chen Y, Chen Y, Tan ZR, Zhou HH (2009) Effect of silymarin on the pharmacokinetics of losartan and its active metabolite E-3174 in healthy Chinese volunteers. Eur J Clin Pharmacol 65(6):585-591. https://doi. org/https://doi.org/10.1007/s00228-009-0624-9

71. Han Y, Guo D, Chen Y, Tan ZR, Zhou HH (2009) Effect of continuous silymarin administration on oral talinolol pharmacokinetics in healthy volunteers. Xenobiotica 39(9):694-699. https://doi.org/https://doi.org/10.1 080/00498250903060077

72. Barnes J, Anderson LA, Phillipson JD (2001) St John's wort (Hypericum perforatum L.): a review of its chemistry, pharmacology and clinical properties. J Pharm Pharmacol 53(5):583-600. https://doi.org/https://doi. org/10.1211/0022357011775910

73. Markowitz JS, Donovan JL, DeVane CL, Taylor RM, Ruan Y, Wang JS, Chavin KD (2003) Effect of St John's wort on drug metabolism by induction of cytochrome P450 3A4 enzyme. J Am Med Assoc 290(11):1500-1504. https:// doi.org/https://doi.org/10.1001/jama.290.11.1500 
74. Durr D, Stieger B, Kullak-Ublick GA, Rentsh KM, Steinert HC, Meier PJ, Fattinger K (2000) St John's wort induces intestinal P-glycoprotein/MDR1 and intestinal and hepatic CYP3A4. Clin Pharmacol Ther 68(6):598-604 https://doi.org/https://doi.org/10.1067/mcp.2000.112240

75. Venkatakrishnan K, Greenblatt DJ, Von Moltke LL, Schmider J, Harmatz JS, Shader RI (1998) Five distinct human cytochromes mediate amitriptyline N-demethylation in vitro: dominance of CYP 2C19 and 3A4. J Clin Pharmacol 38(2):112-121. https://doi.org/https://doi.org/10.1 002/j.1552-4604.1998.tb04399.x

76. Schmider J, Greenblatt DJ, Harmatz JS, Shader RI (1996) Enzyme kinetic modelling as a tool to analyse the behaviour of cytochrome P450 catalysed reactions: application to amitriptyline $\mathrm{N}$-demethylation. $\mathrm{Br}$ J Clin Pharmacol 41(6):593-604. https://doi.org/https://doi.org/10.1046/j.13 65-2125.1996.35717.x

77. Uhr M, Steckler T, Yassouridis A, Holsboer F (2000) Penetration of amitriptyline, but not of fluoxetine, into brain is enhanced in mice with blood-brain barrier deficiency due to Mdr1a P-glycoprotein gene disruption. Neuropsychopharmacology 22(4):380-387. https://doi.org/https://doi.org/1 0.1016/S0893-133X(99)00095-0

78. Andreas J, Jurgen S, Jurgen B, Andreas S, Elke S, Steffen B, Gudrun S, Matthias L, Ivar R (2002) Decreased plasma levels of amitriptyline and its metabolites on comedication with an extract from St. John's wort (Hypericum perforatum). J Clin Psychopharmacol 22:46-54

79. Andren L, Andreasson A, Eggertsen R (2007) Interaction between a commercially available St. John's wort product (Movina) and atorvastatin in patients with hypercholesterolemia. Eur J Clin Pharmacol 63(10):913-916. https://doi.org/https://doi.org/10.1007/s00228-007-0345-x

80. Dresser G, Schwarz UL, Wilkinson GR, Kim RB (2003) Coordinate induction of both cytochrome P4503A and MDR1 by St John's wort in healthy subjects. Clin Pharmacol Ther 73(1):41-50. https://doi.org/https://doi.org/10.1067/ mcp.2003.10

81. Mai I, Bauer S, Perloff E, Johne A, Uehleke B, Frank B, Budde K, Roots I (2004) Hyperforin content determines the magnitude of the St John's wortcyclosporine drug interaction. Clin Pharmacol Ther 76(4):330-340. https:// doi.org/https://doi.org/10.1016/j.clpt.2004.07.004

82. Barone GW, Gurley BJ, Ketel BL, Lightfoot ML, Abul-Ezz SR (2000) Drug interaction between St. John's wort and cyclosporine. Ann Pharmacother 34(9):1013-1016. https://doi.org/https://doi.org/10.1345/aph.10088

83. Moschella C, Jaber BL (2001) Interaction between cyclosporine and Hypericum perforatum (St. John's wort) after organ transplantation. Am J Kidney Dis 38(5):1105-1107. https://doi.org/https://doi.org/10.1053/ajkd.2 001.28617

84. Johne A, Brockmoller J, Bauer S, Maurer A, Langheinrich M, Roots I (1999) Pharmacokinetic interaction of digoxin with an herbal extract from St John's wort (Hypericum perforatum). Clin Pharmacol Ther 66(4):338-345. https:// doi.org/https://doi.org/10.1053/cp.1999.v66.a101944

85. Mueller SC, Uehleke B, Woehling H, Petzsch M, Majcher-Peszynska J, Hehl EM, Sievers H, Frank B, Riethling A-K, Drewelow B (2004) Effect of St John's wort dose and preparations on the pharmacokinetics of digoxin. Clin Pharmacol Ther 75(6):546-557. https://doi.org/https://doi.org/10.1016/j.clpt.2 004.01.014

86. Eich-Hochli D, Oppliger R, Golay KP, Baumann P, Eap CB (2003) Methadone maintenance treatment and St. John's wort: a case report Pharmacopsychiatry 36(1):35-37. https://doi.org/https://doi.org/10.1055/s-2 003-38090

87. Frye R, Fitzgerald S, Lagattuta T, Hruska M, Egorin M (2004) Effect of St John's wort on imatinib mesylate pharmacokinetics. Clin Pharmacol Ther 76(4):323-329. https://doi.org/https://doi.org/10.1016/j.clpt.2004.06.007

88. Smith P, Bullock J, Booker B, Hass C, Berenson C, Jusko W (2004) The influence of St. John's wort on the pharmacokinetics and protein binding of imatinib mesylate. Pharmacotherapy 24(11):1508-1514. https://doi.org/ https://doi.org/10.1592/phco.24.16.1508.50958

89. Piscitelli SC, Burstein AH, Chaitt D, Alfaro RM, Falloon J (2000) Indinavir concentrations and St John's wort. Lancet 355(9203):547-548. https://doi. org/https://doi.org/10.1016/S0140-6736(99)05712-8

90. Mathijssen RHJ, Verweij J, De Bruijn P, Loos WJ, Sparreboom A (2002) Effects of St. John's wort on irinotecan metabolism. J Natl Cancer Inst 94(16):12471249. https://doi.org/https://doi.org/10.1093/jnci/94.16.1247

91. de Maat MM, Hoetelmans RM, Mathôt RA, van Gorp EC, Meenhorst PL, Mulder JW, Beijnen JH (2001) Drug interaction between St John's wort and nevirapine. AIDS 15:420-421
92. Roddy E (2004) Bupropion and other non-nicotine pharmacotherapies. BMJ 328(7438):509-511. https://doi.org/https://doi.org/10.1136/bmj.328.7438.509

93. Fugh-Berman A, Ernst E (2001) Herb-drug interactions: review and assessment of report reliability. Br J Clin Pharmacol 52(5):587-595. https:// doi.org/https://doi.org/10.1046/j.0306-5251.2001.01469.x

94. Parker V, Wong AHC, Boon HS, Seeman MV (2001) Adverse reactions to St John's wort. Can J Psychiatr 46(1):77-79. https://doi.org/https://doi.org/10.11 77/070674370104600112

95. Dannawi M (2002) Possible serotonin syndrome after combination of buspirone and St John's wort. J Psychopharmacol 16(4):401. https://doi. org/10.1177/026988110201600420

96. Kim KA, Park PW, Park JY (2009) Short-term effect of quercetin on the pharmacokinetics of fexofenadine, a substrate of P-glycoprotein, in healthy volunteers. Eur J Clin Pharmacol 65 6:609-614. https://doi.org/https://doi. org/10.1007/s00228-009-0627-6

\section{Publisher's Note}

Springer Nature remains neutral with regard to jurisdictional claims in published maps and institutional affiliations.

\section{Submit your manuscript to a SpringerOpen ${ }^{\circ}$ journal and benefit from:}

- Convenient online submission

- Rigorous peer review

- Open access: articles freely available online

- High visibility within the field

- Retaining the copyright to your article

Submit your next manuscript at $\boldsymbol{\nabla}$ springeropen.com 